\title{
Brain size and urbanization in birds
}

\author{
Anders Pape Møller ${ }^{1 *}$ and Johannes Erritzøe ${ }^{2}$
}

\begin{abstract}
Background: Brain size may affect the probability of invasion of urban habitats if a relatively larger brain entails superior ability to adapt to novel environments. However, once urbanized urban environments may provide poor quality food that has negative consequences for normal brain development resulting in an excess of individuals with small brains.

Methods: Here we analyze the independent effects of mean, standard deviation and skewness in brain mass for invasion of urban habitats by 108 species of birds using phylogenetic multiple regression analyses weighted by sample size.

Results: There was no significant difference in mean brain mass between urbanized and non-urbanized species or between urban and rural populations of the same species, and mean brain mass was not significantly correlated with time since urbanization. Bird species that became urbanized had a greater standard deviation in brain mass than non-urbanized species, and the standard deviation in brain mass increased with time since urbanization. Brain mass was significantly left skewed in species that remained rural, while there was no significant skew in urbanized species. The degree of left skew was greater in urban than in rural populations of the same species, and successfully urbanized species decreased the degree of left skew with time since urbanization. This is consistent with the hypothesis that sub-optimal brain development was more common in rural habitats resulting in disproportionately many individuals with very small brains.
\end{abstract}

Conclusions: These findings do not support the hypothesis that large brains promote urbanization, but suggest that skewness has played a role in the initial invasion of urban habitats, and that variance and skew in brain mass have increased as species have become urbanized.

Keywords: Birds, Brain mass, Skewness in Brain Mass, Standard deviation in Brain Mass, Urbanization

\section{Background}

Species with large brains have been suggested to be particularly successful as reflected by establishment success when introduced to oceanic islands (Sol and Lefebvre 2000; Sol et al. 2002, 2005). If large brains facilitate invasions, we should expect that species with large brains for their body size would be more successful in establishing populations in urban environments. Four studies have investigated this suggestion. First, Kark et al. (2007) found no significant difference in relative brain mass after adjusting for body mass in a small sample of bird species in Jerusalem. Second, Carrete and Tella (2011) showed that bird species with large brains for their body size were more likely to successfully invade urban

\footnotetext{
* Correspondence: anders.moller@u-psud.fr

'Laboratoire d'Ecologie, Systématique et Evolution, CNRS UMR 8079,

Université Paris-Sud, Bâtiment 362, F-91405 Orsay Cedex, France

Full list of author information is available at the end of the article
}

environments in Argentina. Third, Evans et al. (2011) did not find that interspecific differences in brain size accounted for differences in population density between rural and urban habitats. Finally, Maklakov et al. (2011) showed that bird families that had a larger fraction of species breeding in city centers (according to Croci et al. 2008) had large brains for their body size. Thus two studies suggest that mean brain mass, adjusted for the effects of body mass, predict different aspects of urban invasion. However, these analyses did not address whether mean brain mass or a third variable correlated with mean brain mass accounted for the relationship between successful urban invasion and brain size. Here we explicitly test if mean brain size, variance in brain size or skewness in brain size account for differences in urbanization.

Large brains are more costly to produce and maintain than small brains because of their antioxidant requirements (e.g. Bains and Shaw 1997; Hoffman and Heinz 
1998; Sewalk et al. 2001), and the high rate of energy use by brain tissue (Laughlin et al. 1998; Nilsson 1999; Ames 2000; Laughlin 2001). Therefore, more nutrients and energy are allocated to a large brain (Laughlin et al. 1998; Nilsson 1999; Ames 2000; Laughlin 2001), development of a large brain produces more free radicals (e.g. Bains and Shaw 1997; Hoffman and Heinz 1998; Sewalk et al. 2001), and a large brain may take longer time to develop (Ricklefs 2004). Thus developing a large brain may increase the risk that individuals encounter periods with inadequate food or nutrient supply such as antioxidants. A recent study of brain size in birds exposed to radiation from Chernobyl showed a surplus of individuals with small brains in areas with high levels of radiation (Møller et al. 2011). Because ionizing radiation produces large amounts of free radicals, these are eliminated by antioxidants that are generally strongly limiting in radioactively contaminated areas (Møller et al. 2005). Because normal brain development produces large amounts of free radicals, animals living in radioactively contaminated areas suffer from reduced brain development (Møller et al. 2011). Studies of brain size (Nyagu and Loganovsky 1998) and brain function in humans exposed to radiation (Almond et al. 2007; Heiervang et al. 2010) have shown a surplus of individuals with small brains and poor brain function. Therefore, an environment characterized by high production of free radicals and high use and/or low availability of antioxidants, such as radioactively contaminated areas, may cause inferior brain development, leading to greater variances and more left skewed frequency distributions of brain size.

The objectives of this study were to test (1) if mean, variance and skew in brain mass explained variation in successful urbanization, as expected if species with large brains, species with homogeneous brain sizes and species with frequency distributions of brain mass without skew facilitate invasion of urban habitats; (2) if mean, variance and skew in brain mass have increased from the ancestral rural to the current urban populations of the same species, as expected if urban habitats provide food of low quality; and (3) if mean, variance and skew in brain mass in urban populations have changed with time since urbanization, as expected if urbanization has led to local adaptation to urban environments. To this end we exploited a unique dataset on brain mass of birds collected during the last 40 years.

\section{Methods}

\section{Brain and body mass}

Brain mass was derived from post-mortem examinations of dead birds that had been frozen and measured by JE on a precision balance to the nearest $0.001 \mathrm{~g}$, blindly with respect to the hypotheses under test. A detailed description of the standardized preparation procedure that relies on extraction and weighing of the entire brain can be found on the web site of JE (http://www.birdresearch.dk/). Almost all specimens came from Southern Denmark, and hence urban and rural birds originated from the same general area. The general public delivered all specimens, and there is no reason to believe that there is any bias in the data. In brief, JE during standard preparation of bird skins removed the brain from the skull and placed it on a piece of paper on the precision balance. All brains were carefully inspected for any damage due to collision or other causes, and only undamaged brains were included in the samples. Body mass was recorded on a precision balance to the nearest $0.1 \mathrm{~g}$. We assumed that storage and preparation effects on measurements only resulted in random noise in the data, although all specimens were prepared in the same way by the same person. Mean brain sizes for different species were significantly positively correlated with those reported in the literature (e.g. Crile and Quiring 1940; Portmann 1947; Armstrong and Bergeron 1985; Mlikovsky 1990), providing a large and highly significant repeatability $(F=119.37$, d.f. $=34,206, p<0.001 ; R=0.980)$. This justifies that the data are reliably reflecting true brain size. The current database used for the present study consisted of brain mass for 2721 individuals, given the requirement that all individuals should belong to species that allowed estimates of mean, standard deviation and skewness. Sample sizes differed among analyses due to missing values for some species (for example, information on whether a species was urbanized or not was available for more species than which year a species was urbanized). Therefore, we report sample sizes for all analyses in the tables.

\section{Defining urbanization and timing of urbanization}

We defined urban areas as built-up areas with continuous one-family houses and multi-storey buildings with interspersed areas of roads, parks and gardens. In contrast, nearby rural areas consisted of farmland, forests, moors, lakes and other habitats with scattered houses and farms. This operational definition is similar to that provided by Klausnitzer (1989), Gliwicz et al. (1994) and Stephan (1999). We used two criteria for defining successful urbanization: (1) Higher population density of breeding birds in urban than in nearby rural habitats, and (2) timing of urbanization (Møller et al. 2012).

Higher population density of breeding birds in urban than in rural habitats. We used extensive published information on the population density of breeding birds to determine whether a species could be considered to be urbanized or not, using Cramp and Perrins (1977-1994) and (Glutz von Blotzheim and Bauer 1966-1997) as sources. These two main handbooks on the birds of the Western Palearctic have collated information in a similar, consistent and stringent way, allowing comparison among species. This information was combined with our 
own experience and that of colleagues working on urban birds. For a species to be classified as urbanized it should fulfill two criteria: (1) It should have populations breeding inside towns and cities, and (2) population densities in towns and cities should in at least one city be higher in urban than in nearby rural habitats. This resulted in a total of 63 urbanized species out of the 526 species of breeding birds.

Timing of urbanization. Bird species that have been urbanized since long will have spent more generations in urban areas, and hence will have had longer time to adapt to this novel environment. We estimated the approximate year of urbanization in cities in Denmark as described in detail by Møller (2008, 2009, 2010). Thus information on brain size and urbanization originated from the same area. Timing of urbanization will result from colonization followed by establishment, or extinction and perhaps subsequent re-colonization. Obviously, there is no information on such processes, nor is there empirical information about the development of urban population sizes since colonization. Here we assume that colonization of urban environments can be approximated from observations by keen ornithologists who habitually closely follow changes in composition and distribution of birds in the neighborhood where they live. Any heterogeneity in colonization processes or increase in population size will cause noise in the data and ultimately make it more difficult to discern any patterns. We estimated the year when different species became urbanized using two different approaches. First, we asked keen amateur ornithologists to state when different species of birds were first recorded breeding in urban areas. An approximate year of urbanization was recorded, with a conservative value of 1950 assigned to species that were known to breed in urban habitats before the observers started watching birds. Second, we recorded timing of invasion of urban environments from old published records going back the start of the 1900's. If the year of urbanization was before records reported in these sources, we assigned 1850 as the year of urbanization. Although urbanization is likely to have occurred much earlier for many species that are closely associated with humans such as house sparrow Passer domesticus and rock pigeon Columba livia, these estimates are conservative. See Møller (2008, 2009, 2010) and Møller et al. (2012) for a detailed description of this approach and for statistically significant cross-validation among observers, cities and methods. All data are reported in Additional file 1: Tables S1 and S2.

\section{Statistical analyses}

We used $\log _{10}$-transformed brain mass for different species in the statistical analyses. We tested if brain mass was positively correlated with a standard measure of skeletal body size (tarsus length), as would be expected if there was allometry. We found only very weak evidence of allometry because $\log _{10}$-transformed brain mass only increased weakly with $\log _{10}$-transformed tarsus length in a model that also included species as a random factor (partial effect of tarsus length in an analysis of all individuals with information on brain mass and tarsus length: $F=23.29$, d.f. $=1,3333, r^{2}=0.007, p<0.0001$, partial $r=0.08$ ). Therefore, we did not consider this marginal effect of allometry in the subsequent analyses. However, the conclusions of the subsequent analyses reported in the Results do not change if tarsus length was entered as a covariate.

We calculated mean, standard deviation and skewness in brain mass for each species, but also separately for samples from rural and urban populations of the same species and used these estimates in the subsequent analyses. We did not use coefficient of variation because it is a composite variable that depends on both mean and standard deviation. Hence, the use of coefficient of variation would make interpretation difficult. Standard deviation generally increases with mean, and this problem was addressed by inclusion of both variables as predictors. We analyzed whether presence or absence of urbanization was related to body mass, brain mass, SD in brain mass and skewness in brain mass in a phylogenetic multiple regressions weighted by sample size (Table 1). In a second series of intraspecific analyses we used paired t-tests to analyze if rural and urban mean brain mass, SD in brain mass and skewness in brain mass differed significantly (Table 2). Finally, we tested whether year of urbanization was related to body mass, brain mass, SD in brain mass and skewness in brain mass in a phylogenetic multiple regressions weighted by sample size (Table 3). Although body mass was correlated with mean brain mass and standard deviation in brain mass, multicollinearity as assessed by the Variance Inflation Factor (VIF) did not bias parameter estimates in the models. VIF ranged between 1 and 3, i.e. well below the commonly accepted threshold of 5-10 that indicates serious collinearity problems (McClave and Sincich 2003).

Most statistical analyses assume that data points provide equally precise information about the deterministic

\begin{tabular}{|c|c|c|c|c|c|}
\hline Variable & $F$ & $p$ & Slope & SE & Effect size \\
\hline Body mass & 0.06 & 0.95 & 0.001 & 0.024 & 0.05 \\
\hline Brain mass & 3.00 & 0.095 & 0.026 & 0.015 & 0.31 \\
\hline SD brain mass & 5.22 & 0.031 & 0.052 & 0.023 & 0.40 \\
\hline Skewness brain mass & 10.20 & 0.0036 & -0.248 & 0.078 & 0.52 \\
\hline
\end{tabular}

The models were weighted by sample size. Effect size was estimated as Pearson's product-moment correlation coefficient. 
Table 2 Mean (SE) for brain mass, SD in brain mass and skewness in brain mass for matched rural and urban populations of 71 species of birds

\begin{tabular}{|c|c|c|c|c|c|c|c|}
\hline Variable & Rural mean & Rural SE & Urban mean & Urban SE & $t$ & $p$ & Effect size \\
\hline Mean & 1.799 & 1.119 & 0.807 & 1.118 & 0.858 & 0.39 & 0.103 \\
\hline SD & 0.176 & 1.109 & 0.185 & 1.108 & 0.697 & 0.49 & 0.084 \\
\hline Skewness & 0.157 & 0.110 & -0.288 & 0.104 & -2.756 & 0.0075 & 0.315 \\
\hline
\end{tabular}

The t-test is a paired t-test for the difference between rural and urban populations. The models were weighted by sample size. Effect size was estimated as Pearson's product-moment correlation coefficient.

part of total process variation, i.e. the standard deviation of the error term is constant over all values of the predictor variable (Sokal and Rohlf 1995). Garamszegi and Møller (2010) showed that bias due to variation in sample size is as large a problem in comparative analyses as considering species as statistically independent observations. If this assumption of even sampling effort is violated, weighting each observation by sampling effort allows the use of all data, giving each datum a weight that reflects its degree of precision due to sampling effort (Draper and Smith 1981; Neter et al. 1996; Garamszegi and Møller 2010). This procedure will also allow both rare and common species to be included and hence avoid any bias in sampling due to rarity. We weighted comparative statistical models by sample size, estimating weights for each contrast by calculating the mean sample size for the taxa immediately subtended by that node in the phylogeny (Møller and Nielsen 2007). Thus if sample size for two branches was 5 and 10, respectively, the sample size at the node connecting these two species and hence the weight was $(5+10) / 2=7.5$.

We evaluated the magnitude of associations between predictor and response variables using effect sizes estimated as Pearson's product-moment correlation coefficient based on the standard conversion of F-statistics into Pearson's r (Rosenthal 1994). Cohen (1988) proposed explicit criteria for judging whether effects are small (Pearson $r=0.10$, explaining 1\% of the variance), intermediate $(r=0.30,9 \%$ explaining of the variance) or large ( $r=0.50$, explaining $25 \%$ of the variance), and we adopt these criteria here.

We analyzed the relationship between urbanization and the three first moments (mean, variance, skew) of brain mass and body mass, but also the relationship between year of urbanization and the three moments of brain mass using a phylogenetic approach to control statistically for the fact that observations for different species are not statistically independent (Felsenstein 1985). We calculated statistically independent linear contrasts as implemented in the Apple Macintosh-based software CAIC v2.6.9, using the CRUNCH algorithm for continuous variables and the BRUNCH algorithm for discrete variables (Purvis and Rambaut 1995). We constructed a composite phylogeny of all species in our database, based on Davis (2008). The phylogeny is shown in Additional file 1: Figure S1. All branches were assigned the same length although analyses performed assuming uneven branch lengths produced similar results (details not shown). Deleting contrasts with extreme residuals to test for robustness of the conclusions (Purvis and Rambaut 1995) did not change the results. Contrasts were analyzed by forcing regressions through the origin, because the dependent variable is not expected to have changed if there is no change in the independent variable (Harvey and Pagel 1991). All analyses were made with JPM version 10.0 (SAS Institute Inc 2012).

\section{Results}

Brain mass and invasion of urban areas

Species that have become urbanized differed from nonurbanized species by being more variable in brain mass (as reflected by the standard deviation) and having a higher degree of left skewed brain mass than nonurbanized species (Table 1; Figure 1A and B), with effect sizes being intermediate to large. In contrast, body mass and mean brain mass were not significant predictors of urbanization (Table 1).

Table 3 Phylogenetic analysis of year when different species of birds became urbanized in relation to body mass and the first three moments of brain mass

\begin{tabular}{llllllll}
\hline Variable & Sum of squares & d.f. & $\boldsymbol{F}$ & $\boldsymbol{p}$ & Estimate & SE & Effect size \\
\hline Body mass & 6578.35 & 1 & 1.55 & 0.21 & 27.69 & 22.24 & 0.12 \\
Brain mass & 314.30 & 1 & 0.07 & 0.79 & 10.57 & 38.86 & 0.03 \\
SD in brain mass & 66134.38 & 1 & 15.58 & 0.0001 & -63.70 & 16.14 & 0.36 \\
Skewness in brain mass & 74147.01 & 1 & 17.46 & $<0.0001$ & 12.17 & 2.91 & 0.38 \\
Error & 437295.56 & 103 & & & &
\end{tabular}

The model had the statistics $F=12.89$, d.f. $=4,103, r^{2}=0.11, p<0.0001$. The model was weighted by sample size. Effect size was estimated as Pearson's productmoment correlation coefficient. 


\section{Divergence in brain mass between rural and urban populations}

The only significant difference in brain mass between rural and urban populations of the same species was a higher degree of left skew in urban populations (Table 2; Figure 2). The relationship between the other two moments of brain mass and urban or rural habitat had small effect sizes and were not significant (Table 2).

Time since urbanization was significantly negatively related to standard deviation in brain mass, and degree of left skew increased with time since urbanization with an intermediate to large effect size (Table 3; Figure 3A and $\mathrm{B})$. In contrast, the relationship for mean brain mass and time since urbanization was not statistically significant (Table 3).

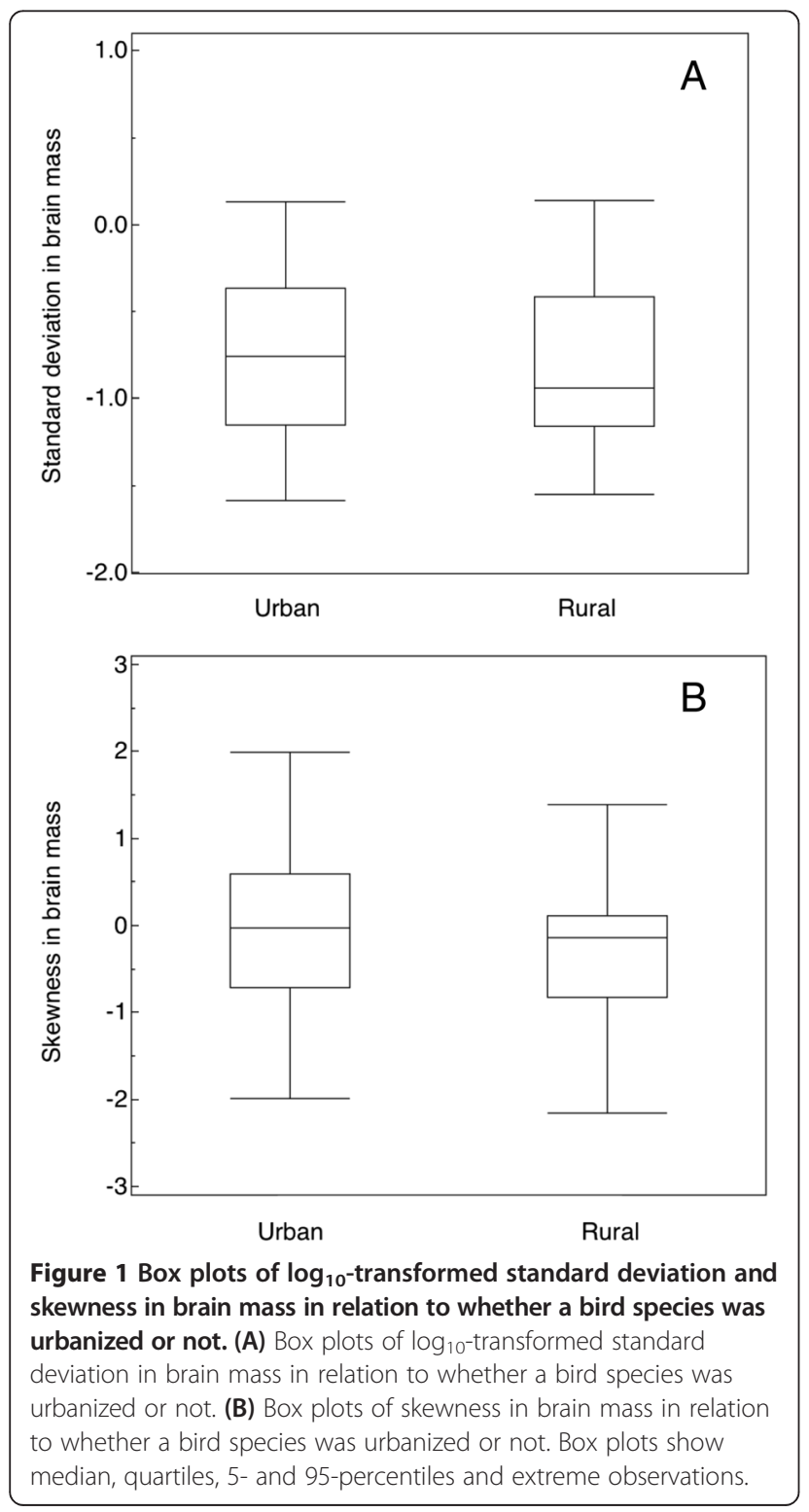

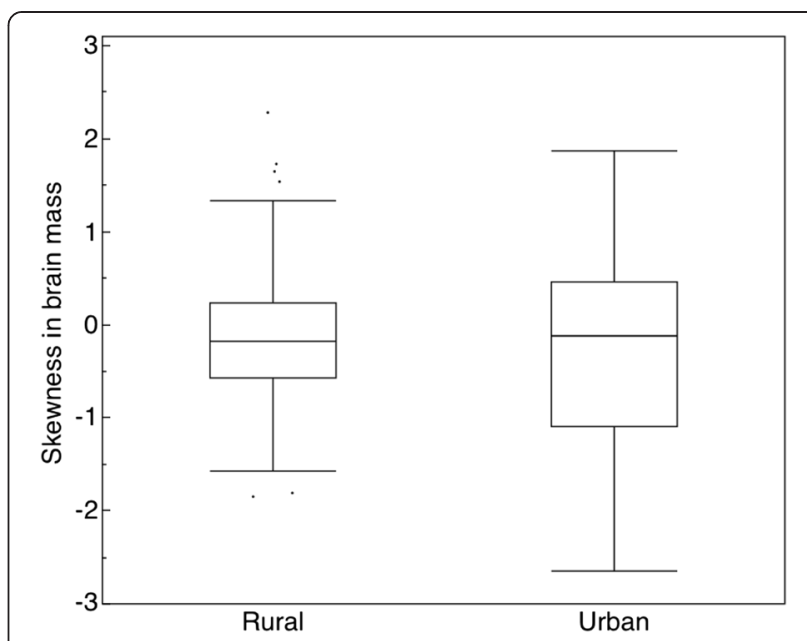

Figure 2 Box plot of skewness in brain mass in rural and urban populations of the same species of birds. The box plot shows median, quartiles, 5- and 95-percentiles and extreme observations.

\section{Discussion}

Bird species that became urbanized had greater variance and less skew in brain mass compared to species that remained rural, while there was no significant difference in body mass or mean brain mass for the two categories of species. There were also significantly greater skew in frequency distributions of brain mass in urban compared to rural populations of the same species. Variance in brain mass decreased and the degree of left skew in brain mass increased with time since urbanization. These findings imply that aspects of brain size differed between species that successfully invaded urban areas and species that remained rural, but also that frequency distributions of brain size diverged between rural and urban populations of the same species following initial urbanization.

Previous studies of brain size and urbanization have either compared the fraction of species in different families that were urbanized in relation to relative brain size (Maklakov et al. 2011), or the relationship between degree of urbanization and relative brain size in different species (Kark et al. 2007; Carrete and Tella 2011; Evans et al. 2011). Here we analyzed the three first moments (mean, standard deviation, skewness) of brain size and invasion of urban habitats based on 108 species. While standard deviation and skewness in brain mass predicted urbanization, there was no evidence that mean brain mass or body mass were significant predictors. These novel findings arise from the broader range of moments included in the present analyses compared to those in previous publications.

The present study is the first to address whether urbanization is associated with divergence in relative brain size between neighboring populations inhabiting rural and urban habitats. Urban populations have 

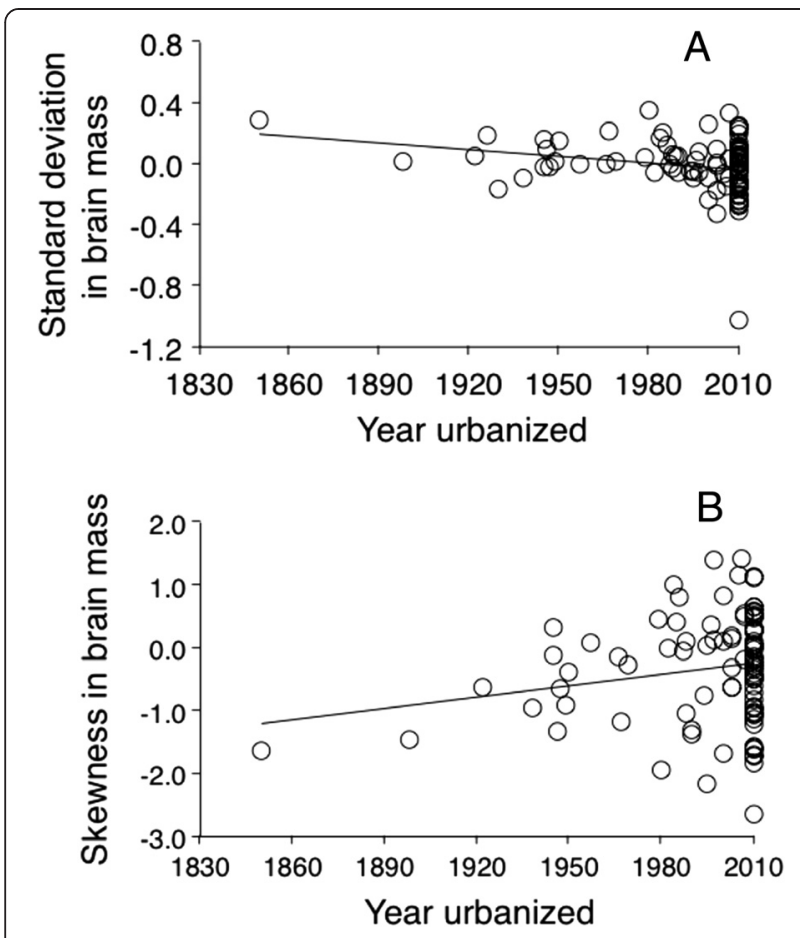

Figure 3 Standard deviation in brain mass and skewness in brain mass in relation to year of urbanization. Standard deviation (A) and (B) skewness were adjusted for the other predictor variables in Table 3. The lines are the linear regression lines. Observations are species-specific values.

diverged genetically from nearby rural populations, and different urban habitats also show significant genetic divergence (Fulgione et al. 2000; Rutkowski et al. 2005; Baratti et al. 2009; Evans et al. 2009; Björklund et al. 2010). A higher degree of left skew in brain mass in urban populations compared to nearby rural populations of the same species suggests that urban habitats may constitute inferior habitats for normal brain development or that urban habitats allow for the survival of a broader spectrum of phenotypes. This hypothesis is supported by the fact that levels of vitamin $\mathrm{E}$ are considerably lower in urban than in rural populations of the same species (Møller et al. 2010). This divergence in vitamin $E$ levels between rural and urban habitats increased with time since urbanization and the number of generations in urban environments (Møller et al. 2010). An alternative explanation is that a high degree of left skew in brain mass in urban compared to rural habitats reflects less intense selection against individuals with small brains in urban environments. This hypothesis is unlikely, given that urban birds that had fallen prey to cats had lower levels of vitamin $\mathrm{E}$ in the liver than nonprey of the same species (Møller et al. 2010), and that lower levels of vitamin $\mathrm{E}$ were associated with development of small brains (Møller et al. 2011).
Brain size of birds became more variable and more left skewed with time since urbanization (Table 3). These two effects were statistically independent (Table 3), suggesting that a larger variance was not a simple consequence of left skewed frequency distributions. Therefore, the greater variance in brain size since urbanization is consistent with the a priori prediction that urban populations become adapted to diverse urban habitats (Møller 2010, 2011). The higher degree of left skew in brain mass in urban habitats suggests that quality or quantity of food in urban environments does not allow all individuals to develop normal sized brains. Experimental studies based on variation in quality of food support this assumption (Bonaparte et al. 2011). Because normal brain development requires large amounts of antioxidants, the low levels of vitamin $\mathrm{E}$ in livers of urban compared to rural birds (Møller et al. 2010) may cause a large fraction of individuals developing small-sized brains.

\section{Conclusions}

Variance and skewness in brain size of birds predicted initial probability of invasion of urban habitats, and variance and skewness in brain size subsequently changed as species became adapted to the urban environment. However, there was no evidence that mean brain mass played a role in any of these processes.

\section{Additional file}

Additional file 1: Table S1. Summary information on whether of not bird species were urbanized ( 0 - no, 1 - yes), year when the species was urbanized (species not yet urbanized were recorded as 2010), log brain mass, log SD in brain mass, skewness in brain mass, log body mass and sample size. Table S2. Summary information on log brain mass, log SD in brain mass, skewness in brain mass and sample size for rural and urban populations of different species of birds. Figure S1. Phylogenetic relationships among species of birds used in the study of brain size and urbanization. See Methods for further details.

\section{Competing interests}

The authors declare that they have no competing interests.

\section{Authors' contributions}

JE measured brain sizes. APM analyzed the data and wrote the manuscript. Both authors read and approved the final manuscript.

\section{Author details}

'Laboratoire d'Ecologie, Systématique et Evolution, CNRS UMR 8079, Université Paris-Sud, Bâtiment 362, F-91405 Orsay Cedex, France. ${ }^{2}$ Taps Old Rectory, DK-6040 Christiansfeld, Denmark.

Received: 8 November 2014 Accepted: 15 March 2015

Published online: 15 May 2015

\section{References}

Almond D, Edlund L, Palmer M (2007) Chernobyl's subclinical legacy: Prenatal exposure to radioactive fallout and school outcomes in Sweden. Natl Bureau Econ Res 13347:1-50

Ames A (2000) CNS energy metabolism as related to function. J Neurosci 34:42-68 Armstrong E, Bergeron R (1985) Relative brain size and metabolism in birds. Brain Behav Evol 26:141-153 
Bains JS, Shaw CA (1997) Neurodegenerative disorders in humans: The role of glutathione in oxidative stress-mediated neuronal death. Brain Res Rev 25:335-358

Baratti M, Cordaro M, Dessi-Fulgheri F, Vannini M, Fratini S (2009) Molecular and ecological characterization of urban populations of the mallard (Anas platyrhynchos) in Italy. Ital J Zool 76:330-339

Björklund M, Ruiz I, Senar JC (2010) Genetic differentiation in the urban habitat: The great tits (Parus major) of the parks of Barcelona city. Biol J Linn Soc 99:9-19

Bonaparte KM, Riffle-Yokoi C, Burley NT (2011) Getting a head start: Diet, sub-adult growth, and associative learning in a seed-eating passerine. PLoS One 6(9):e23775

Carrete M, Tella JL (2011) Inter-individual variability in fear of humans and relative brain size of the species are related to contemporary urban invasion in birds. PLoS One 6(4):e18859

Cohen J (1988) Statistical Power Analysis for the Behavioral Sciences, 2nd edn. Lawrence Erlbaum, Hillsdale, NJ

Cramp S, Perrins CM (eds) (1977-1994) The Birds of the Western Palearctic. Vols 1-9. Oxford University Press, Oxford, UK

Crile G, Quiring DP (1940) A record of the body weight and certain organ and gland weight of 3690 animals. Ohio J Sci 40:219-259

Croci S, Butet A, Clergeau P (2008) Does urbanization filter birds on the basis of their biological traits? Condor 110:223-240

Davis KE (2008) Reweaving the tapestry: a supertree of birds. PhD Thesis. University of Glasgow, Glasgow, Scotland

Draper NR, Smith H (1981) Applied Regression Analysis, 2nd edn. John Wiley, New York, NY

Evans KL, Gaston KJ, Frantz AC, Simeoni M, Sharp SP, McGowan A, Dawson DA, Walasz K, Partecke J, Burke T, Hatchwell BJ (2009) Independent colonization of multiple urban centres by a formerly forest specialist bird species. Proc $\mathrm{R}$ Soc Lond B 276:2403-2410

Evans KL, Chamberlain DE, Hatchwell BJ, Gregory RD, Gaston KJ (2011) What makes an urban bird? Global Change Biol 17:32-44

Felsenstein J (1985) Phylogenies and the comparative method. Am Nat 125:1-15

Fulgione D, Rippa D, Procaccini G, Milone M (2000) Urbanisation and the genetic structure of Passer italiae (Viellot 1817) populations in the south of Italy. Ethol Ecol Evol 12:123-130

Garamszegi LZ, Møller AP (2010) Effects of sample size and intraspecific variation in phylogenetic comparative studies: A meta-analytic review. Biol Rev 85:797-805

Gliwicz J, Goszczynski J, Luniak M (1994) Characteristic features of animal populations under synurbanization: The case of the Blackbirds and the striped field mouse. Mem Zool 49:237-244

Glutz von Blotzheim UN, Bauer KM (eds) (1966-1997) Handbuch der Vögel Mitteleuropas Band. Aula-Verlag, Wiebelsheim, Germany

Harvey PH, Pagel M (1991) The Comparative Method in Evolutionary Biology. Oxford University Press, Oxford, UK

Heiervang KS, Mednick S, Sundet K, Rund BR (2010) Effect of low dose ionizing radiation exposure in utero on cognitive function in adolescence. Scand $J$ Psychol 51:210-215

Hoffman DJ, Heinz GH (1998) Effects of mercury and selenium on glutathione metabolism and oxidative stress in mallard ducks. Environ Toxicol Chem 17:161-166

Kark S, Iwaniuk A, Schalimtzek A, Banker E (2007) Living in the city: Can anyone become an 'urban exploiter'? J Biogeogr 34:638-651

Klausnitzer B (1989) Verstädterung von Tieren. Neue Brehm-Bücherei, Wittenberg Lutherstadt, Germany

Laughlin SB (2001) Energy as a constraint on the coding and processing of sensory information. Curr Opin Neurobiol 11:475-480

Laughlin SB, van Steveninck RRD, Anderson JC (1998) The metabolic cost of neural information. Nat Neurosci 1:36-41

Maklakov AA, Immler S, Gonzalez-Voyer A, Rönn J, Kolm N (2011) Brains and the city: Big-brained passerine birds succeed in urban environments. Biol Lett 7:730-732

McClave JT, Sincich T (2003) Statistics, 9th edn. Prentice-Hall, Englewood Cliffs, NJ

Mlikovsky J (1990) Brain size in birds: 4. Passeriformes. Acta Soc Zool Bohemoslov 54:27-37

Møller AP (2008) Flight distance of urban birds, predation and selection for urban life. Behav Ecol Sociobiol 63:63-75

Møller AP (2009) Successful city dwellers: A comparative study of the ecological characteristics of urban birds in the Western Palearctic. Oecologia 159:849-858

Møller AP (2010) Interspecific variation in fear responses predicts urbanization in birds. Behav Ecol 21:365-371
Møller AP, Nielsen JT (2007) Malaria and risk of predation: A comparative study of birds. Ecology 88:871-881

Møller AP, Surai PF, Mousseau TA (2005) Antioxidants, radiation and mutation in barn swallows from Chernobyl. Proc R Soc Lond B 272:247-253

Møller AP, Erritzøe J, Karadas F (2010) Levels of antioxidants in rural and urban birds and their consequences. Oecologia 163:35-45

Møller AP, Bonisoli-Alquati A, Rudolfsen G, Mousseau TA (2011) Chernobyl birds have smaller brains. PLoS One 6(2):e16862

Møller AP, Diaz M, Flensted-Jensen E, Grim T, Ibáñez-Álamo JD, Jokimäki J, Mänd R, Marko G, Tryjanowski P (2012) High urban population density of birds reflects their timing of urbanization. Oecologia 170:867-875

Neter J, Kutner MH, Nachtsheim CJ, Wasserman W (1996) Applied Linear Statistical Models. Irwin, Chicago, IL

Nilsson GE (1999) Brain and body oxygen requirements of Gnathonemus petersii, a fish with an exceptionally large brain. J Exp Biol 199:603-607

Nyagu Al, Loganovsky KN (1998) Neuro-psychiatric Effects of lonizing Radiation. Chernobylinterinform, Kiev, Ukraine

Portmann A (1947) Etudes sur la cérébralisation chez les oiseaux. Alauda 15:1-15

Purvis A, Rambaut A (1995) Comparative analysis by independent contrasts (CAIC): an Apple-Macintosh application for analyzing comparative data. Comput Appl Biosci 11:247-251

Ricklefs RE (2004) The cognitive face of avian life histories. Wilson Bull 116:119-133

Rosenthal R (1994) Parametric measures of effect size. In: Cooper H, Hedges LV (eds) The Handbook of Research Synthesis. Russell Sage Foundation, New York, NY, pp 231-244

Rutkowski R, Rejt L, Gryczynska-Siematkowska A, Jagolkowska P (2005) Urbanization gradient and genetic variability of birds: Example of kestrels in Warsaw. Berkut 14:130-136

SAS Institute Inc (2012) JMP version 10. SAS Institute Inc, Cary

Sewalk CJ, Brewer GL, Hoffman DJ (2001) Effects of diquat, an aquatic herbicide, on the development of mallard embryos. J Toxicol Environ Health A 62:33-45

Sokal RR, Rohlf FJ (1995) Biometry. Freeman, New York, NY

Sol D, Lefebvre L (2000) Behavioural flexibility predicts invasion success in birds introduced to New Zealand. Oikos 90:599-605

Sol D, Timmermans S, Lefebvre L (2002) Behavioural flexibility and invasion success in birds. Anim Behav 63:495-502

Sol D, Duncan RP, Blackburn TM, Cassey P, Lefebvre L (2005) Big brains, enhanced cognition, and response of birds to novel environments. Proc Natl Acad Sci U S A 102:5460-5465

Stephan B (1999) Die Amsel. Neue Brehm-Bücherei. Wittenberg-Lutherstadt, Germany

\section{Submit your next manuscript to BioMed Central and take full advantage of:}

- Convenient online submission

- Thorough peer review

- No space constraints or color figure charges

- Immediate publication on acceptance

- Inclusion in PubMed, CAS, Scopus and Google Scholar

- Research which is freely available for redistribution

Submit your manuscript at www.biomedcentral.com/submit

C Biomed Central 